\title{
Chile: aspectos naturais e conservação
}

\section{EDSON STRUMINSKI*}

\begin{abstract}
RESUMO
O autor realizou recentemente algumas visitas a unidades de conservação e áreas naturais da República do Chile, em diferentes regiões daquele país. A partir das informações coletadas, objetivou-se apresentar uma análise dos aspectos naturais e sobre os esforços conservacionistas daquele país.
\end{abstract}

Palavras-chave: Cone Sul, biodiversidade, áreas protegidas.

\begin{abstract}
Chile: natural resources and conservation. The author recently made same treckings in conservation units and natural areas at Republic of Chile through different regions of that country. Based on informations collected the objective is to present a research of the natural resources and about the conservacionists efforts of that country.
\end{abstract}

Key words: South America protected natural areas, biodiversity

\section{INTRODUÇÃO}

Existe uma visão simplista que imagina o Chile como sendo um país espremido entre as montanhas da Cordilheira dos Andes e o oceano Pacífico.

$\mathrm{Na}$ realidade, muito embora na sua porção mais larga o país não exceda $450 \mathrm{~km}$, existem diversos ecossistemas vinculados às enormes variações climáticas, que existem no país, tanto no sentido norte-sul, quanto leste-oeste.

Isto implica em uma razoável diversidade de ecossistemas e de espécies que podem ser observadas, de forma especialmente privilegiada, nas diversas unidades de conservação, que ocupam praticamente um quinto do país.

O objetivo deste trabalho é apresentar uma análise dos aspectos naturais e da biodiversidade, bem como dos esforços e das dificuldades do Sistema de Unidades de Conservação daquele país.

\footnotetext{
* Engenheiro Florestal, M.Sc.
} 


\section{METODOLOGIA}

Para que pudessem ser caracterizadas as variações de ambientes existentes no Chile, realizou-se uma série de visitas a diferentes regiões do país, durante os anos de 1997 e 1998. As regiões visitadas foram as seguintes:

- Costa litorânea do Oceano Pacífico (cidades de Constitución e Valdivia), planícies entremeadas por blocos rochosos;

- Cordilheira da costa, montanhas que acompanham o litoral;

- Cordilheira dos Andes (sul do Chile), com grandes extensões de florestas nativas, e/ou unidades de conservação, altitudes menores (no máximo 4.000 metros) e muitos vulcões (alguns ativos);

- Pré-Cordilheira (zona central do Chile), montanhas de arenito;

- Cordilheira dos Andes (Cajón del Maipo na zona central do Chile), com grandes montanhas, áreas nevadas e desertos de altitude e,

- Vale Central (capital Santiago e arredores), planalto antropizado.

Nestas regiões foram visitadas várias unidades de conservação e áreas naturais. Em paralelo, contatos foram realizados com técnicos da CONAF (Corporación Nacional Forestal), ambientalistas e andinistas (freqüentadores assíduos destas áreas). As informações coletadas foram confrontadas com dados bibliográficos, a partir do que produziu-se o presente trabalho.

\section{REVISÃO BIBLIOGRÁFICA}

Pode-se distinguir as seguintes formações de relevo no Chile de oeste para leste e suas respectivas vegetações naturais, tomando-se como exemplo a zona central (HOFFMANN, 1992):

- Zonas costeiras (oceano Pacífico), com planícies formadas por desembocaduras de rios, onde encontram-se ervas, arbustos e árvores perenes ou anuais. Estas planícies podem ser entremeadas por áreas com grandes blocos rochosos que permitem o acúmulo de solo e o desenvolvimento de espécies endêmicas (no Brasil seriam classificadas como Formação Pioneira "litoral rochoso"), além de servirem de abrigo para a fauna (como constatou-se in loco). O clima é suave e úmido com variações moderadas de temperatura no dia e ao longo do ano, até onde vai a ação reguladora dos ventos marítimos;

- A cordilheira da costa, com montanhas até 2000 metros de altitude. Na face voltada para o oceano prevalece o clima mais regular com umidade constante proveniente dos ventos marinhos carregados de sal. Arbustos e árvores de pequeno porte, além de grande número de ervas caracterizam a fisionomia da região. Verificou-se que grandes áreas estão convertidas à produção florestal com espécies exóticas (Pinus);

- “Quebradas" costeiras, vales onde encontra-se vegetação mais densa com grande número de espécies, muitas de uso tradicional como medicinais, confecção de móveis, lenha, frutos, artesanato, etc., tais como: 
Myrceugenia, Beilsch, Cryptocarya, Aristotelia, Persea, Nothofagus, ou ainda o bambu, Chusquea cumingii, com destaque para o "canelo" (Drimys winteri), árvore sagrada dos índios araucanos que ocorre também no Brasil. Em condições pedológicas especiais pode aparecer a "palma chilena", Jubaea chilensis, muito explorada para extração de mel (geralmente com a morte da árvore).

Nos cerros mais altos, a vegetação torna-se arbustiva e escassa, podendo ocorrer nevadas no inverno. Na face sul destas montanhas podem aparecer associações mais densas, inclusive do boldo chileno Peumus boldus, árvore que alcança até 15 metros de altura. Nas faces norte aparecem bromélias, belos cactos colunares (Trichocereus), arbustos xerofíticos espinhosos e abundante tapete herbáceo, configurando o "matorral mediterrâneo";

- A depressão intermediária ou vale central (cerca de $1100 \mathrm{~km}$ entre os $30^{\circ}$ e $40^{\circ}$ sul). Terreno plano onde vivem cerca de $90 \%$ da população do país (não mais de $30 \%$ do país é plano). Ali, desenvolvem-se atividades agrícolas, pecuária, indústrias e encontram-se as principais cidades do país. Nas áreas não alteradas, encontra-se a "estepe de espinho", com ervas anuais que reverdecem quando há umidade. Freqüentemente é queimada nos verões quentes e secos. Acacia caven ("espino") é espécie arbórea de pequeno porte que caracteriza a associação, muito usada para lenha ou carvão;

- E finalmente a cordilheira dos Andes, formada por altas montanhas (até 6800 metros de altitude), com muitos vulcões, neves eternas e geleiras, que são a fonte da água potável consumida no país.

Nos Andes, encontram-se vários habitats e comunidades vegetais conforme a variação da altitude. Existem igualmente diferenças nas exposições norte-sul e nas "quebradas" onde se conserva a umidade durante o ano todo.

Até cerca de 1.500 metros, encontramos o "matorral mediterrâneo" típico, que vai reduzindo seu porte até os 2.000 metros. Acima desta altitude estes arbustos não ultrapassam os $50 \mathrm{~cm}$ de altura, geralmente retorcidos. Nas porções mais altas, até os 3.500 metros, sujeitas a nevadas, só se encontram, de forma esparsa, pequenas herbáceas da flora andina.

A primavera chega mais tarde a esta região do que no vale central, devido ao acúmulo de neve invernal. Assim, o fim de dezembro e janeiro correspondem a setembro e outubro no vale. Nas áreas mais baixas, entretanto, mantem-se vegetação até o outono, composto por espécies de caráter medicinal da montanha, que são buscadas por animais para pasto.

$\mathrm{Na}$ área continental do Chile encontramos ainda três tipos climáticos principais (CIREN-CORFO, 1994), distribuídos de norte a sul:

- Clima seco ao norte, entre aproximadamente os $18^{\circ}$ e $30^{\circ}$ de latitude sul (200 a 1.000 mm de precipitação; temperaturas médias entre os $20^{\circ}$ e $25^{\circ} \mathrm{C}$ e mínimas a $0^{\circ} \mathrm{C}$ ). Nesta região encontra-se o deserto do Atacama, com $180.000 \mathrm{~km}^{2}$, sendo a vegetação predominante arbustiva ou inexistente; 
- Clima mesotérmico ou mediterrâneo entre os $30^{\circ}$ e $37^{\circ}$ sul $(500$ a $2.000 \mathrm{~mm}$ de precipitação; temperatura média de $20^{\circ} \mathrm{C}$ e mínimas a $0^{\circ} \mathrm{C}$ ), ao norte mais desértico e ao sul mais úmido, com temporada de seca no verão; típico do vale central, com vegetação predominante arbustiva e arbórea de pequeno porte (que lembra fisionomicamente a caatinga nordestina); e,

- Clima úmido entre os $37^{\circ}$ e $55^{\circ}$ sul (até $7.500 \mathrm{~mm}$ de precipitação em forma de neve; temperaturas médias entre $10^{\circ}$ e $15^{\circ}$ e mínimas a $0^{\circ}$ ). Encontramse florestas temperadas abundantes e exuberantes.

\section{RESULTADOS E DISCUSSÃO}

Devido às grandes variações climáticas, reconhece-se no Chile a existência de 8 regiões ecológicas, com 83 formações vegetais ou ecossistemas, sendo que destes, foram detectados 12 tipologias tipicamente florestais, em geral classificadas de acordo com as espécies dominantes (CHILE, 1991). Assim sendo, existe, por exemplo, a tipologia ARAUCARIA, na qual a espécie Araucaria araucana pode encontrar-se em forma pura ou mesclada com outras espécies como Nothofagus dombeyi, Nothofagus pumilio, Nothofagus obliqua, Nothofagus antarctica ou Drimys winteri. Espécies do gênero Nothofagus aparecem, aliás, em quase todos os tipos florestais do país.

Apesar de limitada, é bastante interessante a diversidade florística do país. Segundo informações prestadas ao autor, o herbário do Museu de História Natural do Chile, contém cerca de 100 mil coletas, correspondendo a $80 \%$ da flora do país. ZEGERS (1991) cita, por exemplo, nove espécies de coníferas nativas dos gêneros Araucaria, Podocarpus, Austrocedrus, Fitzroya, Pilgerodendron e Saxegothaea (as coníferas Araucaria e Podocarpus também ocorrem no Brasil), além de 42 espécies de folhosas, de gêneros típicos da região, como o já citado Nothofagus, ou outros de ocorrência também no Brasil, como Schinus, Persea, Myrceugenia (com várias espécies já consideradas raras no Chile), além de Drimys, já citado.

Porém, assim como no Brasil, dos cerca de 7,49 milhões de hectares de florestas nativas, VALENZUELA (1991) e CIREN-CORFO (1994) consideram que extensas áreas (em torno de 3,6 milhões de hectares) já estão degradadas e empobrecidas pela exploração irracional, ou incêndios, sem uma silvicultura que permita a sustentabilidade da floresta.

As demais áreas florestais correspondem a 1,75 milhão de hectares de plantios, iniciados a partir da década de 1940 em terrenos montanhosos, que envolvem em geral Pinus radiata (1,37 milhão de hectares) e Eucalyptus sp., que como no Brasil são as espécies sobre as quais está calcada a indústria de transformação mecânica e química do país.

A flora não arbórea chilena corre risco ainda de extinção pela exploração para comércio de produtos com características comerciais (como o caso do famoso boldo do Chile), pelo avanço da desertificação (norte do Chile), ou pela substituição por reflorestamentos homogêneos. 
A introdução de espécies exóticas também afeta este tipo de vegetação. Devido à extrema simplificação, o ambiente onde estas espécies ocorrem é bastante vulnerável ao estabelecimento de espécies mais agressivas. No Monumento Nacional El Morado (Zona Central - Cordilheira dos Andes), segundo informações prestadas pelos administradores da unidade, de 280 espécies encontradas, 32 são exóticas, sendo que 45 são raras, pouco freqüentes ou com distribuição geográfica naturalmente reduzida pelas montanhas.

Já o Sistema Nacional de Áreas Protegidas do Chile (SNASPE), a cargo da Corporación Nacional Forestal (CONAF), apresenta algumas peculiaridades que o diferenciam do Brasil. De forma discreta os chilenos já transformaram, desde 1907, a respeitável soma de mais de $19 \%$ do seu território em unidades de conservação, sendo um país líder neste aspecto.

Esta transformação envolve, segundo VALENZUELA (comunicação oral), 94 unidades e 14,3 milhões de hectares cobrindo 54 dos 83 ecossistemas naturais que ocorrem no país. Teria havido assim um progresso recente em relação ao que relatou UICN (1993), que registra uma evolução de 1982 (44 dos 83 ecossistemas) a 1988 (51 dos 83 ecossistemas), havendo então 79 unidades de conservação.

Parques Nacionais representam 60,4\% do sistema, Reservas Nacionais (similares às nossas Reservas Biológicas) entram com 39,5\% e Monumentos Naturais (versão menor de um parque nacional) somam $0,1 \%$ ao total (CHILE, 1991). Existem ainda a Reserva de Região Virgem (similar à Estação Ecológica), Área de Proteção Turística e Lugar de Interesse Científico, unidades sob administração de outros organismos governamentais ou privados.

O percentual de $19 \%$ esconde no entanto, algumas distorções do SNASPE chileno. UICN (1993) revela que $82 \%$ das unidades de conservação estão concentradas no sul do país (XI e XII regiões). VALENZUELA (1991) lembra também que apenas 1,98\% (1,5 milhão de hectares) está efetivamente representado por florestas, consideradas como "bosques de proteção" e não de produção, não havendo portanto meios do Estado demonstrar alternativas produtivas para a exploração degradadora das florestas nativas (através, por exemplo, da Floresta Nacional, uma categoria inexistente no Chile). O restante das áreas protegidas são desertos, altas montanhas, campos de gelo, áreas com vegetação de menor porte ou lagos.

Outro indicador importante fornecido por BENOIT (1989) é o da distribuição geográfica de espécies vegetais em risco no país. Assim sendo, de 26 vulneráveis, nenhuma consta oficialmente nas XI e XII regiões (a espécie Araucaria araucana, das VIII e IX regiões, por exemplo, apesar de declarada como Monumento Natural, encontra-se vulnerável, com população em declínio). Já para as 32 raras (com distribuição muito restrita), encontramos apenas 5 nestas respectivas regiões. O SNASPE chileno apresentaria portanto uma lacuna na proteção deste aspecto da biodiversidade.

Assim como ocorre no Brasil, somente as principais unidades de conservação possuem planos de manejo, faltando ainda infraestrutura e pessoal para cobrir os objetivos de vigilância, educação, integração do visitante e 
pesquisa científica. Conflitos entre conservação e exploração existem ainda no sul do Chile, área com muitas unidades de conservação, mas com interesses petrolíferos recentes conflitantes, entre o Chile e sua vizinha Argentina. Até então, a criação de unidades vinha servindo inclusive para sanar problemas de fronteiras entre os dois países.

Também puderam ser observadas distorções dos objetivos de manejo. No Parque Nacional Villarica (Cordilheira dos Andes - sul), a exploração comercial do turismo praticamente inviabiliza qualquer outro uso desta unidade que não seja através das agências de turismo, uma vez que a municipalidade não dispôs transportes públicos para o parque, além do pernoite só ser viabilizado em áreas particulares. Desta forma, a orientação ao visitante recai praticamente sobre critérios turísticos e não educacionais. Também na Reserva Nacional Mocho-Choschuenco (Cordilheira dos Andes - sul), equipamentos de uma estação de esqui e sua infraestrutura de acesso (estradas) encontram-se abandonados, causando problemas de erosão e impacto paisagístico.

Recentemente, tem sido noticiado também na imprensa chilena, a compra de grandes extensões de terras, em especial na Patagônia, por estrangeiros. A polêmica neste assunto surgiu de restrições que poderiam ter os moradores nativos pelo uso dos recursos naturais e de uma eventual estagnação econômica que causaria a conservação em áreas que não as oficiais (parques e unidades equivalentes).

De modo geral, os conflitos surgem devido às limitações econômicas, de recursos naturais e climáticas da região, que têm levado à decadência os usos tradicionais da terra, em prol de opções mais lucrativas de exploração da natureza (como é o caso do turismo), que não estão, entretanto, ainda devidamente avaliadas do ponto de vista do impacto ambiental.

\section{CONCLUSÕES}

Percebeu-se que o SNASPE chileno tem seu principal objetivo em representar inicialmente todos os ecossistemas do país, sobretudo na região centro e norte, antes que espécies importantes da natureza chilena se extingam.

Em paralelo, a administração deste patrimônio crescente se tornará certamente um grande desafio de manejo que só o tempo e a experiência poderão dizer se será bem sucedido.

Entretanto, do ponto de vista conservacionista, mesmo considerando as dificuldades, é sem dúvida relevante os números que o Chile, um país com recursos limitados e sujeito, afinal de contas, a vários dos problemas do "terceiro mundo" e aos efeitos da globalização, já obteve até o momento, com o esforço de seus técnicos e o apoio da população. 


\section{BIBLIOGRAFIA CITADA}

HOFFMANN, J.A. 1995. Flora Silvestre de Chile - Zona Central. Ediciones Fundación Claudio Gay, Santiago, CH. $3^{\mathrm{a}}$ Ed.,237 p.

CIREN-CORFO. 1994. Atlas Forestal de Chile. Corporación Nacional Forestal, Santiago, CH. Informativo $\mathrm{n}^{\mathrm{o}} 103,17 \mathrm{p}$.

CHILE. 1991. Recursos Forestales de Chile. Ministerio de Agricultura - Corporación Nacional Forestal, Santiago, CH. 10 p.

ZEGERS, C.D. 1991. Arboles Nativos de Chile, guia de reconocimiento Marisa Cuneo Ediciones, Valdivia, CH. 78 p.

VALENZUELA, F.U. 1991. El Recurso Forestal en Chile - superficie, ubicación, tenencia, una aproximación. Inédito, Santiago, CH. 14p.

INFOR-CORFO. 1994. El Sector Forestal Chileno. Corporación Nacional Forestal, Santiago, CH. 23 p.

UICN. 1993. Parques y Progreso. Washington, D.C. 88 p.

BENOIT, I.L. 1989. Red Book on Chilean Terrestrial Flora. Corporación Nacional Forestal, Santiago, CH. 103 p.

\section{AGRADECIMENTOS}

Ao senhor Francisco Ulloa Valenzuela, Eng. Florestal do Dpto de Manejo e Desenvolvimento Florestal da CONAF pelas valiosas informações prestadas, que permitiram a produção deste trabalho. 